\title{
PEMBUATAN MESIN SCREW CONVEYOR UNTUK PENCAMPURAN GARAM DAN IODIUM SESUAI SNI 3556
}

\author{
Aenor Rofeg \\ Fakultas Teknik, Program Studi Teknik Mesin \\ Universitas Muria Kudus \\ Email: aenor rofeg@yahoo.co.id \\ Masruki Kabib \\ Fakultas Teknik, Program Studi Teknik Mesin \\ Universitas Muria Kudus \\ Email : masruki.kabib@umk.ac.id \\ Rochmad Winarso \\ Fakultas Teknik, Program Studi Teknik Mesin \\ Universitas Muria Kudus \\ Email : Rochmad.Winarso@umk.ac.id
}

\begin{abstract}
ABSTRAK
Pada proses pencampuran garam dan iodium pada industri umumnya menggunakan proses manual dengan mengaduk di meja atau sejenis cangkul yang mengakibatkan kurang maksimalnya kualitas garam beriodium $S N I$ dan dibutuhkan waktu yang kurang efisien yang bergantung pada tenaga manusia yang cenderung semakin berkurang ketika semakin banyak tenaga di keluarkan. Tujuan dari penelitian ini adalah membuat mesin screw conveyor untuk pencampuran garam dan Iodium sesuai dengan SNI 3556 dengan kapasitas $1400 \mathrm{~kg} / \mathrm{jam}$ yang mampu mencampur garam yang beriodium secara Homogen menggunakan system Screw Conveyor. Tahap pembuatan mesin mencakup pekerjaan: gambar kerja, pemotongan bahan sesuai gambar, pembubutan, pengelasan, perakitan dan uji untuk kerja mesin untuk mengetahui hasil pembuatan mesin. Hasil yang dicapai adalah membuat Mesin Screw Conveyor Untuk Pencampuran Garam dan Iodium Sesuai Dengan SNI 3556 dengan kapasitas $1500 \mathrm{~kg} / \mathrm{jam}$ yang homogen (minimal $30 \mathrm{ppm}$ ). Konstruksi mesin ini cukup sederhana terdiri dari Ribbon (Screw), bearing, V-Belt, puli, elektro motor serta murah dan mudah dalam pengoperasianya
\end{abstract}

Kata kunci : Garam, Iodium, screw conveyor

\begin{abstract}
In the process of mixing salt and iodine in industry generally use manual process by stirring on the table or a kind of hoes that result in less maximum quality of iodine salt SNI and in need of less efficient time dependent on human energy tends to decrease as more energy is spent. The purpose of this research is to make of screw conveyor machines for salt and iodine mixing in accordance with SNI 3556 with the capacity of 1400 kilograms/hour which can mix homogeneous iodine salt using screw conveyor system. The machine making stage includes the work: Work drawing, cutting of material according to drawing, lathe, welding, assembly and test for machine work to know the result of machine making. The result is to make of screw conveyor machines for salt and iodine mixingin accordance with SNI 3556 with capacity of 1400 kilograms/hour which is homogneous (at least 30 ppm). The contruction of thi machine is quite simle consisting of ribbon (screw), bearing, V-belt, pulley, electro motor as well as cheap and easy in operation.
\end{abstract}

Keyword : Salt, Iodium, Screw Conveyor 


\section{PENDAHULUAN}

Kebutuhan garam dari tahun ke tahun semakin meningkat seiring dengan bertambahannya penduduk dan perkembangan industry di Indonesia untuk itu perlu ditingkatkan produksi garam dan kualitasnya. Garam merupakan salah satu kebutuhan pelengkap dari kebutuhan pangan dan merupakan sumber elektrolit bagi tubuh manusia. Walaupun Indonesia termasuk Negara maritim, namun usaha meningkatkan produksi garam belum diminati, termasuk dalam usaha meningkatkan kualitasnya. Di pihak lain untuk kebutuhan garam dengan kualitas baik (kandungan kalsium dan magnesium kurang) banyak diimpor dari luar negeri, terutama garam beriodium serta garam industry. Proses pembuatan garam rakyat adalah proses menguapkan air laut dalam petak-petak tambak garam di pinggir pantai. Air laut setiap liternya yang diuapkan sampai kering mengandung setiap liternya 7 mineral yaitu $\mathrm{CaSO} 4, \mathrm{MgSO} 4, \mathrm{MgCl} 2, \mathrm{KCl}, \mathrm{NaBr}, \mathrm{NaCl}$, dan air dengan berat total 1025,68 gram. Setelah dikristalakn proses selanjutnya akan diperoleh garam dengan kepekatan 16,75-28,50 Be setara dengan 23,3576 gram. [1]

Mesin merupakan sarana yang banyak membantu dalam mempercepat proses produksi, karena mesin dapat bekerja lebih cepat, lebih teliti dan lebih full time. Salah satu jenis mesin yang mungkin dibutuhkan dalam dunia industry ini adalah mesin pencampur garam dan iodium, dimana garam dan iodium hasil pencampuran pada proses akhirnya tercampur secara homogen.

Screw conveyor merupakan salah satu perlengkapan produksi pada suatu perusahaan, screw ini memiliki ulir dan arah putaran searah jarum jam. [2]

Teknologi screw conveyor sangat di butuhkan untuk perindustrian karena akan meningkatkan produksi pencampuran yang homogen, efisiensi, keefektifan dan mengurangi beban kerja karyawan. Alat atau permesinan yang digunakan di industry garam di Indonesia kebanyakan masih manual untuk mencampur garam dan iodium. Hal tersebut sangat penting untuk pencampuran, karena dengan permesinan screw diharapkan mampu tercampur secara homogen. [3]

Industri garam mengalami kesulitan yang cukup besar. Adanya tuntutan terhadap garam yang beriodium sesuai standart SNI 3556 maka dicarilah solusi parameter proses yang tepat, pemilihan alat yang akan digunakan agar diperoleh kualitas pencampuran yang baik dengan sekecil mungkin terjadinya tidak tercampur iodium. Hal tersebut tentu akan sulit jika hanya mengandalkan cara manual, oleh karena itu perancangan Mesin Screw conveyor pencampur garam dan iodium untuk industry dibuat dengan meminimalkan kurang meratanya iodium. Cara kerja mesin ini sendiri yaitu input berupa garam, kemudian screw memutar searah jarum jam akan mengaduk/mentransfer garam sampai ke output, sebelum garam sampai di output, garam di semprotkan/dicampurkan iodium di dekat input. [4]

\section{METODOLOGI}

Metodologi penelitian ini dimualai dari 1.kajian pustaka, gambar, 2. perancangan proses manufaktur yang meliputi : analisa kebutuhan, pemilihan urutan proses pengerjaan screw, perancangan urutan proses assembly, dan perancangan urutan proses finishing, 3. Proses pengerjaan screw conveyor yang meliputi : pengerjaan rangka, pengerjaan poros, pengerjaan screw, pengerjaan hopper dan pengerjaan corong keluar, 4. Perakitan komponen mesin screw conveyor yang meliputi : perakitan rangka, perakitan screw conveyor, perakitan bearing screw, perakitan tabung rumah screw, perakitan bearing poros, perakitan hopper, perakitan corong keluar, perkaitan motor listrik, 5. Proses finishing yang meliputi : menggerinda, mengamplas, dan mengecat.

Desain untuk proses manufaktur dimulai selama tahapan dalam pembuatan alat, sewaktu fungsi-fungsi dan spesifikasi alat ditentukan,. Desain untuk proses manufaktur menggunakan beberapa tipe yang diantaranya adalah sketsa, gambar, spesifikasi alat dan alternatif-alternatif rancangan alat tersebut. Suatu pemahaman detail tentang proses produksi dan perakitan alat dan perkiraan biaya manufaktur 


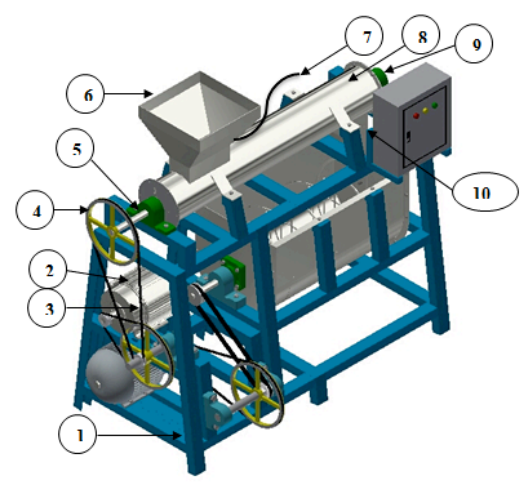

Gambar 1. Mesin Screw Conveyor

Mesin screw conveyor pada gambar 1. Terdiri dari komponen : 1) Rangka mesin, 2) Motor penggerak, 3) V-Belt, 4) pulley, 5) poros, 6) hopper, 7) Aliran $\mathrm{KIO}_{3}$, 8) silider tabung, 9) bantalan, 10) corong keluar.

Prinsip kerja dari mesin screw conveyor kapasitas $6120 \mathrm{~kg} / \mathrm{jam}$ adalah sebagai berikut :

1. Membuat takaran Iodium $\left(\mathrm{KIO}_{3}\right)$ untuk tahapan pencampuran screw conveyor sebesar 30 ppm, yaitu untuk $100 \mathrm{~kg}$ garam Kalium iodatnya yang diperlukan 5 gram, larutan air panas sebesar 0,125 L, dan larutan air Ades 0,250 L. Sesuai kepres RI NO. 691994.

2. Syarat Garam krosok yang akan di proses harus di tiriskan terlebih dahulu.

3. Garam konsumsi di umpankan ke hopper mesin screw conveyor, dalam fase yang sama screw dan aliran $\mathrm{KIO}_{3}$ akan tercampur.

4. Membuat takaran Iodium $\left(\mathrm{KIO}_{3}\right)$ untuk tahapan pencampuran screw conveyor sebesar 30 ppm, yaitu untuk $100 \mathrm{~kg}$ garam Kalium iodatnya yang diperlukan 5 gram, larutan air panas sebesar 0,125 L, dan larutan air Ades 0,250 L. Sesuai kepres RI NO. 691994.

5. Syarat Garam krosok yang akan di proses harus di tiriskan terlebih dahulu.

6. Garam konsumsi di umpankan ke hopper mesin screw conveyor, dalam fase yang sama screw dan aliran $\mathrm{KIO}_{3}$ akan tercampur.

7. Desain screw menggunakan tipe Cut, sehingga Diharapakan proses percampurannya homogen.

8. Screw Mendorong Garam yang sudah tercampur dengan $\mathrm{KIO}_{3}$ menuju corong keluar.

9. Setelah Garam keluar dari corong tersebut, seterusnya garam tersebut di proses dengan mesin mixer.

\section{HASIL DAN PEMBAHASAN}

Dalam proses pembuatan mesin screw conveyor untuk pencampur garam dan iodium ini ada beberapa hal yang harus di perhatikan, yaitu: mempersiapkan bahan, menyediakan alat/mesin yang digunakan, mempersiapkan gambar kerja dan mengikuti urutan langkah kerja sesuai dengan instruksi kerja.

\subsection{Persiapan Bahan}

Kebutuhan bahan dalam proses pembuatan alat mesin screw conveyor untuk pencampur garam dan iodium sebagai berikut:

a). Rangka menggunakan bahan Baja UNP 50 (50x38x5mm) sebanyak 4 buah, b). untuk tabung slinder menggunakan pipa SS $304 \varnothing 6$ in dengan panjang $1000 \mathrm{~mm} 1$ buah, c). untuk cover tabung menggunakan SS 304 dengan ukuran 200x200x3mm sebanyak 4 lembar, d). untuk poros menggunakan SS 304 dengan ukuran Ø 1 in, e). untuk screw menggunakan SS 304 dengan ukuran 150x150x2mm sebanyak 12 lembar, f). untuk hopper menggunakan bahan SS 304 dengan ukuran 300x300x2mm sebanyak 4 lembar, g). untuk corong keluar menggunakan bahan SS 304 dengan 
ukuran 300x200x2mm sebanyak 4 lembar, h). untuk bearing pada tabung menggunakan UCF Ø 25,4 mm sebanyak 2 buah sedangkan untuk poros menggunakan UCP pada rangka sebanyak 2 buah, i). motor listrik menggunakan daya $1 / 2$ HP 1 buah, j). untuk pulley mengunakan bahan alumunium dengan ukuran 2 in sebanyak 2 buah dan 10 in sebanyak 2 buah, k). untuk V-belt menggunakan ukuran A-55 dan A-36.

\subsection{Pembuatan Rangka}
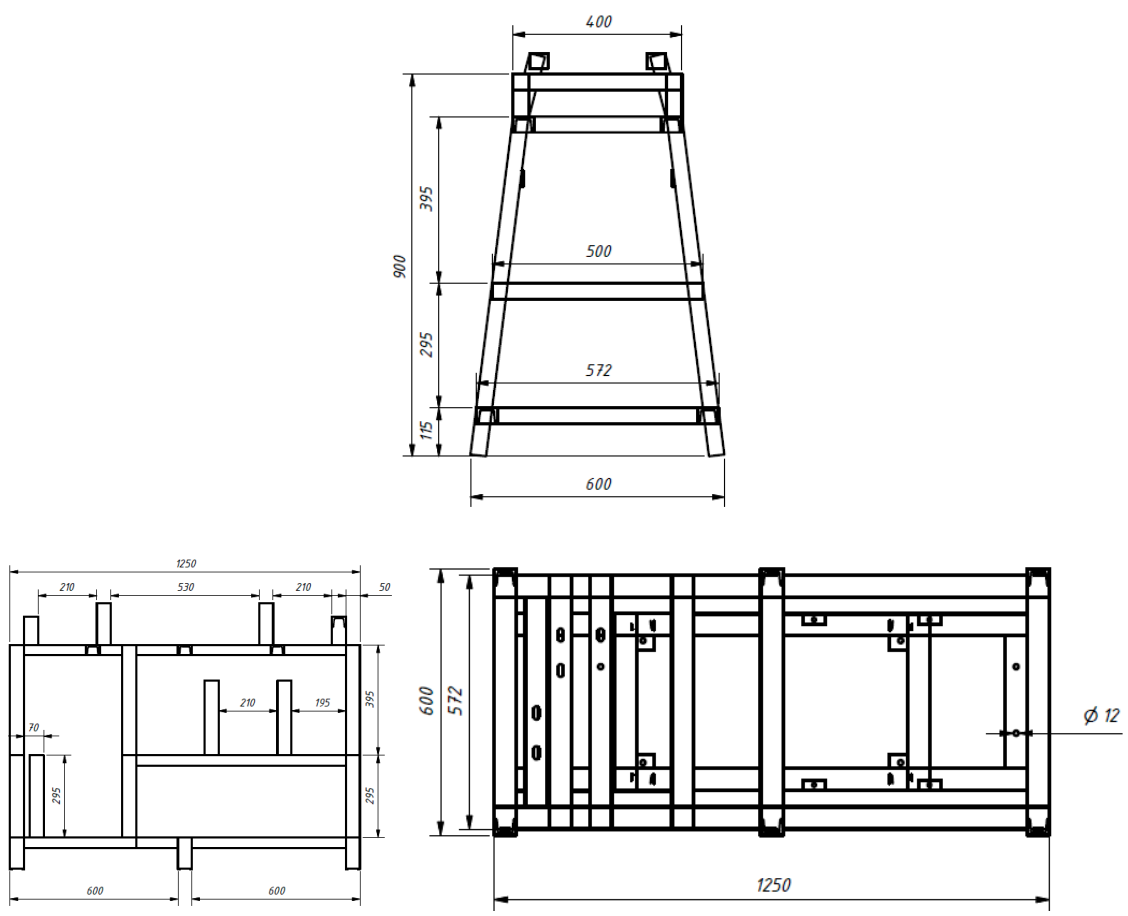

Gambar 2. Desain Rangka

Gambar desain rangka sebagaimana gambar 1. Proses pembuatan rangka meliputi kegiatan sebagaimana pada tabel 1 .

Tabel 1. Proses pengerjaan rangka

\begin{tabular}{lllll}
\hline No & Uruan pengerjaan & Material & Mesin & Ukuran \\
\hline 1 & Pemotongan bahan & Baja UNP 50 & Mesin gerinda & $1150,800,600,520$, \\
& & & $475,400,350$ dan 100 \\
2 & Pengelasan & Baja UNP 50 & Elektroda berdastkan & $1150,800,600,520$, \\
& & standart AWS E6013, & $475,400,350$ dan 100 \\
& & diameter elektroda $=2.6$ & \\
& & & \\
\hline
\end{tabular}




\subsection{Pembuatan Poros Screw Conveyor}

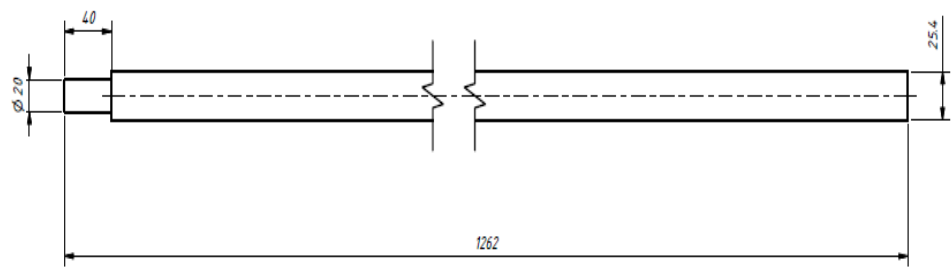

\section{Gambar 3. Poros screw}

Proses pembuatan pada pembuatan poros ini bertujuan untuk mengurangi diameter dan panjang benda kerja agar sesuai dengan ukuran yang terdapat paa gambar kerja. Pembubutan yang dilakukan adalah pembubutan muka (facing), pembubutan rata memanjang, pembubutan rata bertingkat dan chamfer. Proses pembuatan rangka meliputi kegiatan sebagaimana pada tabel 2 .

Tabel 2. Proses pengerjaan poros

\begin{tabular}{lllll}
\hline No & Uruan pengerjaan & Material & Mesin & Ukuran \\
\hline 1 & Pemotongan bahan & SS 304 & Mesin gerinda & 1262 \\
2 & Pembubutan bahan & SS 304 & Mesin bubut & $\varnothing 20$ \\
\hline
\end{tabular}

\subsection{Pembuatan Screw Conveyor}

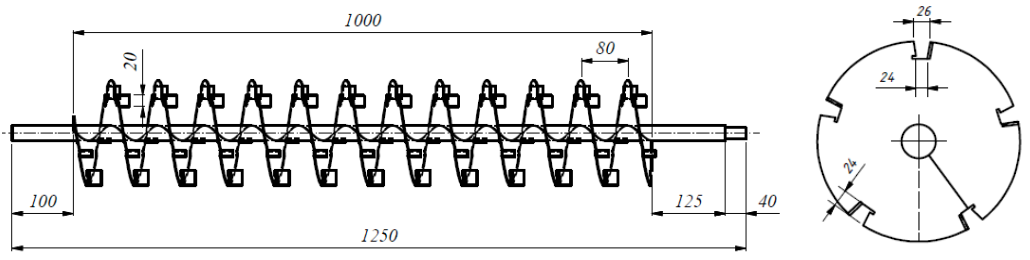

Gambar 4. Screw conveyor

Proses pembuatan screw conveyor seperti pada gambar 4, meliputi pengerjaan sebagaimana pada tabel 3 .

Tabel 3. Proses pengerjaan screw conveyor

\begin{tabular}{lllll}
\hline No & Uruan pengerjaan & Material & Mesin & Ukuran \\
\hline 1 & Pemotongan bahan & SS 304 & Mesin gerinda & $150 \times 12$ lembar \\
2 & Pengelasan & SS 304 & Elektroda berdasrkan & $150 \times 12$ lembar \\
& & & standart AWS E308-16, \\
& & diameter elektroda = 2.6 & \\
& & & \\
& & & \\
\hline
\end{tabular}




\subsection{Pembuatan Hopper}
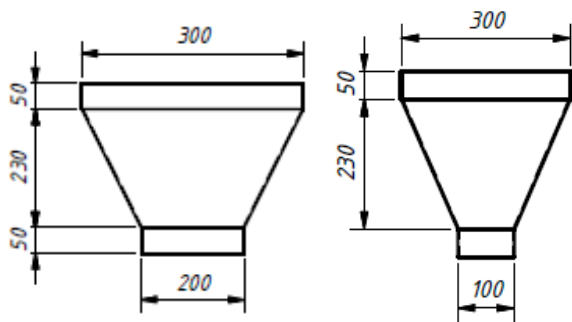

Gambar 5. Hopper

Desain hopper sebagaimana gambar 5. Proses pembuatan hopper meliputi kegiatan sebagaimana pada tabel 4 .

Tabel 4. Proses pengerjaan screw conveyor

\begin{tabular}{lllll}
\hline No & Uruan pengerjaan & Material & Mesin & Ukuran \\
\hline 1 & Pemotongan bahan & SS 304 & Mesin gerinda & $300 \times 200 \times 2,300 \times 100 \times 2$ \\
2 & Pengelasan & SS 304 & Elektroda berdasrkan & $300 \times 200 \times 2,300 \times 100 \times 2$ \\
& & standart AWS E308-16, & \\
& & & diameter elektroda $=$ \\
& & $2.6 \mathrm{~mm}$ & \\
\hline
\end{tabular}

\subsection{Pembuatan Corong Keluar}

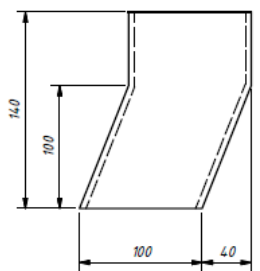

\section{Gambar 6. Corong keluar}

Proses pembuatan corong keluar pada gambar 6, meliputi kegiatan sebagaimana pada tabel 5.

Tabel 5. Proses pengerjaan screw conveyor

\begin{tabular}{lllll}
\hline No & Uruan pengerjaan & Material & Mesin & Ukuran \\
\hline 1 & Pemotongan bahan & SS 304 & Mesin gerinda & $140 \times 100 \times 2$ \\
2 & Pengelasan & SS 304 & Elektroda berdasrkan & $140 \times 100 \times 2$ \\
& & & standart AWS E308-16, \\
& & & diameter elektroda = \\
& & & $2.6 \mathrm{~mm}$ & \\
\hline
\end{tabular}

\subsection{Proses Perakitan}

Proses perakitan merupakan satu rangkaian kegiatan untuk menggabungkan komponen mesin untuk menjadi satu kesatuan sesuai dengan bagian dan fungsinya. 


\subsection{Proses Finishing}

Proses finishing merupakan proses akhir dari proses pembuatan mesin. Proses finishing bertujuan untuk merapikan hasil dari proses pembuatan agar tampilan terlihat bagus. Adapun proses finishing dalam pembuatan mesin pencampur garam dan iodium ini adalah sebagai berikut: 1) Penggerindaan adalah melakukan pengerindaan untuk merapikan dan menghaluskan permukaan serata merapikan bagian-bagian mesin. Waktu yang dibutuhkan pengeridaan 1 jam. Untuk selanjutnya 2) Pendempulan meliputi : mencampurkan depul dan bahan pengerasnya jadi satu dengan secukupnya, Melakukan pendempulan yang bertujuan untuk menutupi pori-pori atau hasil pengelasan yang tidak rata, Biarkan sampai bener-benar kersa atau kering, Lakukan pengamplasan sampai halus dan rata, waktu yang diperlukan dalam pendempulan dan pengamplasan adalah : 4 jam. Yang terakhir yaitu Pengecatan, yang meliputi : Mempersiapkan kompresor dan Spraygun cat, Mencampur cat dan tinner dengan takaran 1: 1,5, Melakukan pengecatan pada rangka dengan jarak $\pm 30 \mathrm{~cm}$, Waktu pengecatan 1 jam.

\subsection{Hasil Pengujian}

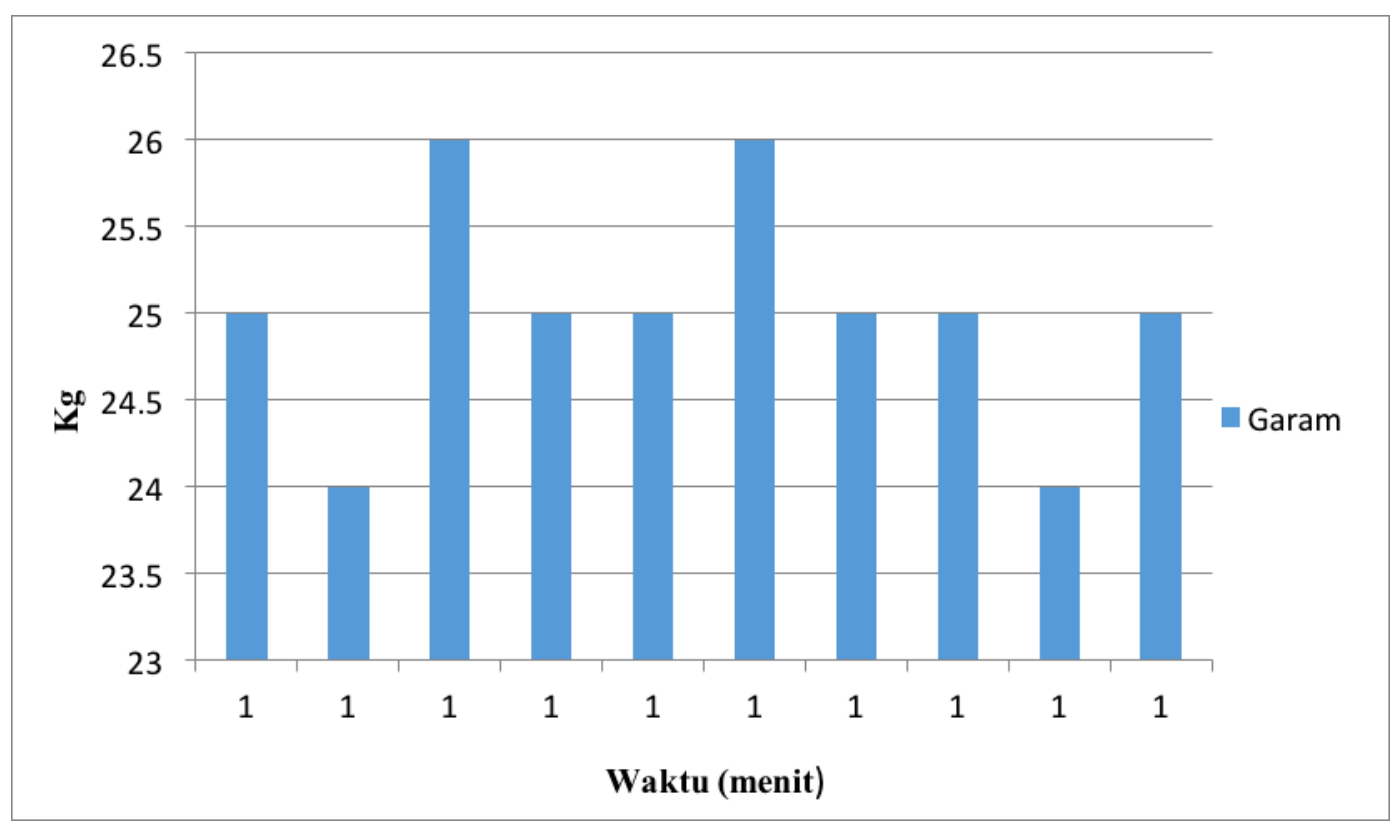

Gambar 7. Grafik data hasil pengujian

Jadi proses pencampuran garam dan iodium ini menghasilkan 1 menit $25 \mathrm{Kg}$ pencampuran garam, maka dilakukan perhitungan $25 \mathrm{Kg}$ x 60 menit $=1500 \mathrm{Kg}$.

\section{KESIMPULAN}

Kesimpulan dalam penelitian menghasilkan mesin Screw conveyor untuk pencampuran garam dan iodium sesuai dengan SNI 3556 dengan menggunakan bahan rangka besi UNP 50 50x38x5mm, sedangkan untuk screw conveyor, hopper, corong keluar menggunakan bahan Stainless Steel 304. Kapasitas produk yang direncanakan dengan menggunakan mesin pencampur garam dan iodium adalah $1400 \mathrm{~kg} / \mathrm{jam}$, dari hasil pengujian mesin pencampuran garam dan iodium di dapatkan kapasitas sebesar $1500 \mathrm{~kg} / \mathrm{jam}$, mengalami peningkatan dari hasil perancangan. 


\section{DAFTAR PUSTAKA}

[1] R. Hartati, E. Supriyo, and M. Zainuri, "Yodisasi garam rakyat dengan sistem screw injection," Gema Teknol., vol. 17, no. 4, pp. 160-163, 2014.

[2] Herlambang, "Proses Perancangan Screw Conveyor," Jakarta, 2015.

[3] Sabardiyanto and N. Iskandar, "Anakisis Mekanik Screw Conveyor Tubular Diameter 200 mm," JTM, vol. 4, no. 2, pp. 178-186, 2016.

[4] D. Handayani, Murni, D. Ikhsan, and F. Arifan, "Peningkatan Produksi Garam Beryodium Melalui Aplikasi Alat Pencetak Garam Secara Mekanik," Semarang, 2008. 